\title{
Red blood cell transfusion
} in the resuscitation of septic patients with hematological malignancies

\author{
Adrien Mirouse ${ }^{1}$, Matthieu Resche-Rigon ${ }^{2}$, Virginie Lemiale ${ }^{3}$, Djamel Mokart ${ }^{4}$, Achille Kouatchet ${ }^{5}$, \\ Julien Mayaux ${ }^{6}$, François Vincent ${ }^{7}$, Martine Nyunga ${ }^{8}$, Fabrice Bruneel $^{9}$, Antoine Rabbat ${ }^{10}$, Christine Lebert $^{11}$, \\ Pierre Perez ${ }^{12}$, Anne Renault ${ }^{13}$, Anne-Pascale Meert ${ }^{14}$, Dominique Benoit ${ }^{15}$, Rebecca Hamidfar ${ }^{16}$, \\ Mercé Jourdain ${ }^{17}$, Michaël Darmon ${ }^{18}$, Elie Azoulay ${ }^{3}$, Frédéric Pène ${ }^{1 *}$ and on behalf of the Groupe de Recherche \\ sur la Réanimation Respiratoire en Onco-Hématologie (Grrr-OH)
}

\begin{abstract}
Background: Indications for red blood cell (RBC) transfusion in septic acute circulatory failure remain unclear. We addressed the practices and the prognostic impact of RBC transfusion in the early resuscitation of severe sepsis and septic shock in patients with hematological malignancies.

Methods: We performed a retrospective analysis of a prospectively collected database of patients with hematological malignancies who required intensive care unit (ICU) admission in 2010-2011. Patients with a main admission diagnosis of severe sepsis or septic shock were included in the present study. We assessed RBC transfusion during the first two days as part of initial resuscitation.

Results: Among the 1011 patients of the primary cohort, 631 (62.4\%) were admitted to the ICU for severe sepsis (55\%) or septic shock (45\%). Among them, 210 (33.3\%) patients received a median of 2 [interquartile 1-3] packed red cells during the first $48 \mathrm{~h}$. Hemoglobin levels were lower in transfused patients at days 1 and 2 and became similar to those of non-transfused patients at day 3. Early RBC transfusion was more likely in patients with myeloid neoplasms and neutropenia. Transfused patients displayed more severe presentations as assessed by higher admission SOFA scores and blood lactate levels and the further requirements for organ failure supports. RBC transfusion within the first two days was associated with higher day 7 (20.5 vs. 13.3\%, $p=0.02$ ), in-ICU (39 vs. 25.2\%, $p<0.001$ ) and in-hospital (51 vs. $36.6 \%, p<0.001$ ) mortality rates. RBC transfusion remained independently associated with increased in-hospital mortality in multivariate logistic regression (OR 1.52 [1.03-2.26], $\mathrm{p}=0.03$ ) and propensity score-adjusted (OR 1.64 $[1.05-2.57], p=0.03)$ analysis.
\end{abstract}

Conclusions: RBC transfusion is commonly used in the early resuscitation of septic patients with hematological malignancies. Although it was preferentially provided to the most severe patients, we found it possibly associated with an increased risk of death.

Keywords: Hematological malignancy, Severe sepsis, Septic shock, Anemia, Red blood cell transfusion

\footnotetext{
*Correspondence: frederic.pene@aphp.fr

${ }^{1}$ Réanimation médicale, hôpital Cochin, Assistance Publique-Hôpitaux

de Paris (AP-HP) and Université Paris Descartes, 27 rue du Faubourg

Saint-Jacques, 75014 Paris, France

Full list of author information is available at the end of the article
} 


\section{Background}

Septic shock is a frequent and dreaded complication in patients with malignancies. Following the overall improvement in the management of the disease, the last two decades have witnessed dramatic improvements in the prognosis of cancer patients presenting with severe sepsis and septic shock [1-4]. A major advance in the general management of sepsis was the implementation of aggressive resuscitation strategies, primarily inspired from the pivotal study by Rivers and colleagues, which promoted a protocol-guided hemodynamic resuscitation based on circulatory and tissue oxygenation objectives, the so-called early goal-directed therapy (EGDT) [5]. The genuine EGDT algorithm included a hematocrit target of $30 \%$ in case of persistent tissue hypoxia. Two-thirds of EGDT-treated patients therefore received red blood cell (RBC) transfusion within the early $72 \mathrm{~h}$ of resuscitation. However, the own prognostic value of RBC transfusion was not specifically assessed. Moreover, the study was performed in the late 1990s at the time when liberal fluid filling accounted for a high incidence of dilution anemia. All three recent replication studies of early goal-directed therapy retrieved lower requirements in $\mathrm{RBC}$ transfusion along with a more restrictive fluid filling policy [6-8]. Indications of $\mathrm{RBC}$ transfusion in the resuscitation of severe sepsis remain unclear [9], and it is noteworthy that the 2012 Surviving Sepsis Campaign guidelines were not able to provide any firm recommendation about the optimal transfusion threshold during hemodynamic instability [10]. Owing to the remaining controversy about optimal hemoglobin thresholds for transfusion in sepsis resuscitation, additional data are needed to optimize practices at the bedside.

Cancer patients with septic shock are at high risk of untractable multiple organ failure within the first days of ICU admission [11]. Early and aggressive resuscitation through restoration of both hemodynamics and tissue oxygenation is a major therapeutic goal in this setting. The optimal threshold for RBC transfusion and the eventual benefit in septic acute circulatory failure are debated. This issue appears particularly relevant to patients with hematological malignancies since the high prevalence of anemia imposed by malignant bone marrow infiltration or by cytotoxic treatments makes them particularly liable to urgent RBC transfusion in this setting in contrast to patients with delayed ICU-acquired anemia. This question was not specifically addressed by the leading trials about transfusion strategies in critically ill patients, since patients with chronic anemia were excluded from the pivotal TRICC trial and cancer patients were underrepresented in the TRISS trial [12-14]. We herein addressed the practices and the prognostic value of RBC transfusion as part of early sepsis resuscitation in a large cohort of patients with hematological malignancies who were admitted to the intensive care unit (ICU) for the main diagnosis of severe sepsis and septic shock.

\section{Patients and methods Study design}

We conducted a substudy of a prospective, multicenter observational study that included 1011 consecutive adult patients with hematological malignancies who required ICU admission in 2010-2011. The study was approved by the appropriate ethics committees in France and Belgium. The methods and primary results of the study have been already published elsewhere [15]. The study involved 17 centers in France and Belgium, which may display different transfusion practices toward patients with hemodynamic instability. Blood banks followed similar national procedures for the collection, pre-storage leucoreduction, storage duration and delivery of $\mathrm{RBC}$ concentrates.

\section{Patients}

We focused on patients with a primary diagnosis of severe sepsis or septic shock according to the common definitions of the Surviving Sepsis Campaign [10]. Briefly, severe sepsis was defined by a clinically or microbiologically documented infection associated with organ failure. Septic shock was defined as an acute circulatory failure requiring vasopressor support. We collected the requirements for RBC transfusion during the first $48 \mathrm{~h}$ as part of initial resuscitation, thereby identifying transfused and non-transfused patients.

The following data were prospectively collected: demographic features (age and gender), performance status prior to the acute complication, comorbidities using the Charlson comorbidity index, features of the underlying hematological malignancy (type of disease, time from diagnosis, status, hematopoietic stem cell transplantation). Newly diagnosed malignancies were defined as diagnosed within the past 4 weeks. The sepsis-related organ failure assessment (SOFA) score was computed on admission then daily throughout the stay in the ICU [16]. The features and management features of sepsis included the primary source of infection and the pathogen involved, as well as requirements for life-supporting interventions including vasopressor support, noninvasive/invasive mechanical ventilation and renal replacement therapy during the ICU stay.

\section{Statistical analysis}

Quantitative variables were described as median [interquartile range] and categorical variables as number (percentage). The primary endpoint was vital status at hospital discharge. Multivariate logistic regression was 
used to assess the impact of day 1-2 transfusion on hospital mortality. The covariates identified as determinants of death in the primary analyses were entered into the model. Log-linearity was checked for continuous variables. Non-log-linear variables were dichotomised. Hosmer-Lemeshow goodness-of-fit tests were performed on multivariate regression models.

In order to limit bias in between-group comparisons, a propensity score-based approach was used to assess the impact of transfusion on hospital mortality, ICU mortality and 7-day mortality. The propensity score was defined as the probability that a patient with specific baseline characteristics receives transfusion. Then, two patients with identical propensity score values can be considered as comparable, and matching on the propensity score has been shown as one of the most efficient method for treatment effect assessment. We computed the propensity score using logistic regression to predict transfusion based on baseline characteristics known to be linked to the mortality and/or possibly to transfusion. Each subject treated by transfusion was randomly selected and then matched (without replacement) to the nearest untreated subject based on calipers of width of 0.2 of the standard deviation of the logit of the propensity score [17]. An inverse probability weighting approach for propensity score was also considered as sensitivity analysis. Missing data were handled using multiple imputation by chained equation. Fifty complete dataset were created using 10 iterations of the chained equation process. Rubin's rules were applied after the evaluation of the treatment effect on each complete dataset.

All tests were two-sided and $p$ values $<0.05$ were considered as indicating significant association. Analyses were performed using the $\mathrm{R}$ statistical software version 2.15.0 (http://www.Rproject.org).

\section{Results}

Among the 1011 patients of the primary cohort, 347 (34.3\%) were admitted to the ICU for severe sepsis and $284(28 \%)$ for septic shock. Of those 631 patients, 210 (33\%) received transfusions of 2 [1-3] packed red cells as part of the initial resuscitation strategy during the first two days in the ICU $(148(23.5 \%)$ and $89(14.5 \%)$ at days 1 and 2, respectively). Among transfused patients, 6 (3\%) presented concurrent bleeding at the time of admission. Hemoglobin levels were lower in transfused patients at day $1(7.8[7.1-8.8]$ vs. $9.7[8.7-11] \mathrm{g} / \mathrm{dL}, \mathrm{p}<0.001)$ and day $2(8.9[7.9-9.9]$ vs. $9.3[8.4-10.2] \mathrm{g} / \mathrm{dL}, \mathrm{p}=0.001)$ and became similar to those of non-transfused patients at day 3 (8.9 [8.2-9.8] vs. 8.9 [8-10]) (Fig. 1).

The other characteristics of non-transfused and transfused patients are shown and compared in Table 1. Early $\mathrm{RBC}$ transfusion was more likely in patients with acute

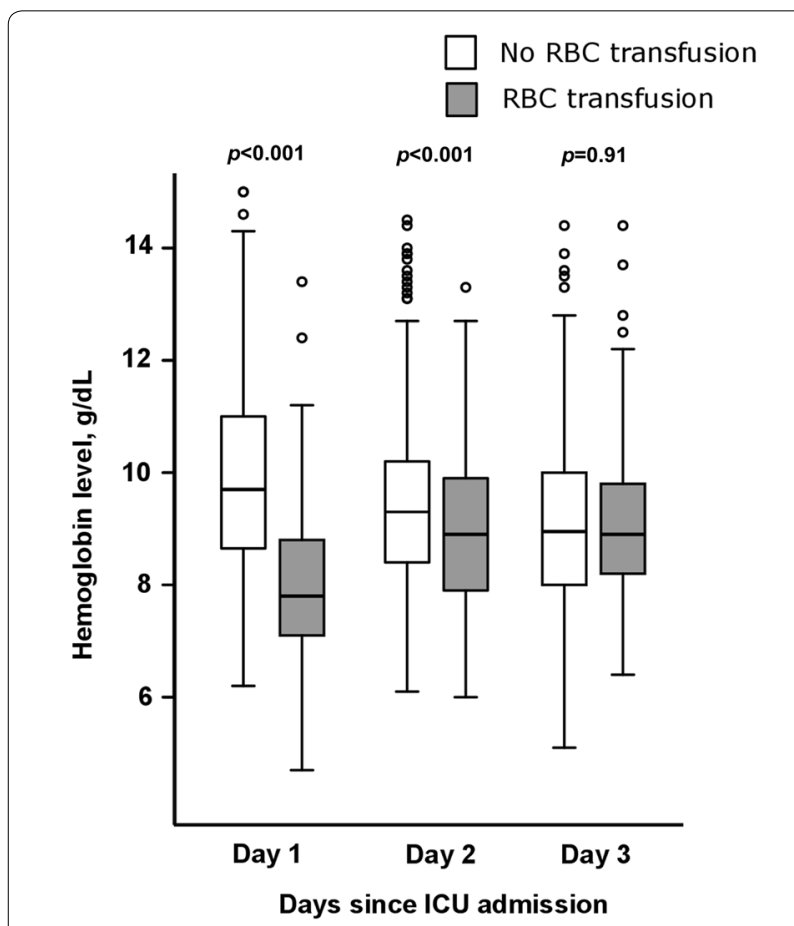

Fig. 1 Hemoglobin levels in non-transfused $(n=421)$ and transfused $(n=210)$ patients. ICU intensive care unit, $R B C$ red blood cell

myeloid leukemia and neutropenia. Transfused patients appeared with more severe presentations and tissue dysoxia as assessed by higher admission SOFA scores $(8$ [5-11] vs. 6 [4-9], p < 0.001), higher blood lactate levels $(2.3[1.5-4.9]$ vs. $2.0[1.2-3.7] \mathrm{mmol} / \mathrm{L}, \mathrm{p}=0.02)$ (Additional file 1: Fig. S1) and the further requirements for organ failure supports including vasopressive drugs (70 vs. $57.7 \%, \mathrm{p}=0.004)$, invasive mechanical ventilation (55.2 vs. $48.7 \%, \mathrm{p}=0.01$ ) and renal replacement therapy (30.5 vs. $22.2 \%, \mathrm{p}=0.03$ ).

The overall in-ICU and in-hospital mortality rates were 28.9 and $41.4 \%$, respectively. In univariate analysis, RBC transfusion within the first $48 \mathrm{~h}$ was associated with increased mortality at day $7(20.5$ vs. $13.3 \%, p=0.02)$, in the ICU (39 vs. $25.2 \%, \mathrm{p}<0.001)$ and in the hospital (51 vs. $36.6 \%, \mathrm{p}<0.001$ ) (Table 2; Fig. 2a). After adjustment with other relevant variables including the hemoglobin level on ICU admission and septic shock, RBC transfusion was no longer associated with 7-day mortality (OR 1.11 [0.66-1.87], $\mathrm{p}=0.7$ ), but tended to be associated with higher in-ICU and in-hospital mortality rate (OR 1.44 [0.94-2.21], $\mathrm{p}=0.09$ and OR 1.52 [1.03-2.26], $\mathrm{p}=0.03$, respectively). Other variables associated with in-hospital mortality were poor performance status, severity on admission as assessed by SOFA score, allogeneic hematopoietic stem cell transplantation, increased time to ICU admission and invasive aspergillosis. Partial 
Table 1 Characteristics of patients without and with red blood cell transfusions at day $1 / 2$

\begin{tabular}{|c|c|c|c|}
\hline Characteristics & $\begin{array}{l}\text { No RBC transfusion } \\
(n=421)\end{array}$ & $\begin{array}{l}\text { RBC transfusion } \\
(n=210)\end{array}$ & $p$ \\
\hline \multicolumn{4}{|l|}{ Demographics } \\
\hline Age (years) & $60[49-71]$ & 60 [49-69] & 0.68 \\
\hline Male gender & $268(63.7 \%)$ & $138(65.7 \%)$ & 0.30 \\
\hline \multicolumn{4}{|l|}{ Comorbid illnesses } \\
\hline Performance status 3-4 & 87 (20.7\%) & $51(24.3 \%)$ & 0.35 \\
\hline Charlson comorbidity index & $4[3-6]$ & $4[2-5]$ & 0.77 \\
\hline Cardiovascular comorbidity & 155 (36.8\%) & $77(36.7 \%)$ & 1 \\
\hline Coronary disease & $31(7.3 \%)$ & $19(9.0 \%)$ & 0.53 \\
\hline Chronic heart failure & $20(4.8 \%)$ & $14(6.7 \%)$ & 0.35 \\
\hline Peripheral arterial disease & $19(4.5 \%)$ & $6(2.8 \%)$ & 0.39 \\
\hline Underlying malignancy & & & 0.01 \\
\hline Non-Hodgkin lymphoma & 149 (35.4\%) & $53(25.2 \%)$ & \\
\hline Hodgkin lymphoma & $13(3.1 \%)$ & $2(1.0 \%)$ & \\
\hline Chronic lymphocytic leukemia & $37(8.8 \%)$ & $13(6.2 \%)$ & \\
\hline Acute lymphocytic leukemia & $23(5.5 \%)$ & $20(9.5 \%)$ & \\
\hline Acute myeloid leukemia & $88(20.9 \%)$ & $69(32.3 \%)$ & \\
\hline Chronic myeloid leukemia & $8(1.9 \%)$ & $4(1.9 \%)$ & \\
\hline Myeloma & $56(13.3 \%)$ & $26(12.4 \%)$ & \\
\hline Myelodysplastic syndrome & $23(5.5 \%)$ & $12(5.7 \%)$ & \\
\hline Others & $24(5.7 \%)$ & $11(5.2 \%)$ & \\
\hline Time between diagnosis and ICU admission (days) & 294 [38-1309] & $199[29-817]$ & 0.06 \\
\hline \multicolumn{4}{|l|}{ Hematopoietic stem cell transplantation } \\
\hline Autologous & $50(11.9 \%)$ & $26(12.4 \%)$ & 0.72 \\
\hline Allogeneic & $77(18.3 \%)$ & $33(15.7 \%)$ & 0.49 \\
\hline \multicolumn{4}{|l|}{ Malignancy status } \\
\hline Newly diagnosed & $120(28.6 \%)$ & $70(33.3 \%)$ & 0.95 \\
\hline Partial/complete remission & 115 (27.5\%) & $54(25.7 \%)$ & 0.54 \\
\hline Time between hospital and ICU admissions (days) & $6[1-21]$ & $8[1-19]$ & 0.38 \\
\hline \multicolumn{4}{|l|}{ ICU admission characteristics } \\
\hline SOFA & $6[4-9]$ & $8[5-11]$ & $<0.001$ \\
\hline Hemoglobin (g/dL) & $9.7[8.7-11]$ & $7.8[7.1-8.8]$ & $<0.001$ \\
\hline Hemoglobin ranges $[n(\%)]$ & & & 0.001 \\
\hline$>9 \mathrm{~g} / \mathrm{dL}$ & $259(66.1 \%)$ & $44(21.9 \%)$ & \\
\hline $7-9 \mathrm{~g} / \mathrm{dL}$ & $126(32.1 \%)$ & $117(58.2 \%)$ & \\
\hline$<7 \mathrm{~g} / \mathrm{dL}$ & $7(1.8 \%)$ & $40(19.9 \%)$ & \\
\hline Platelet count (G/L) & 77 [32-170] & 31 [16-63] & $<0.001$ \\
\hline Neutropenia & $122(29.0 \%)$ & 107 (51.0\%) & $<0.001$ \\
\hline Lactate level (mmol/L) & $2.0[1.2-3.7]$ & $2.3[1.5-4.9]$ & 0.02 \\
\hline \multicolumn{4}{|l|}{ Source of infection } \\
\hline Pneumonia & $252(59.9 \%)$ & $106(50.5 \%)$ & 0.03 \\
\hline Abdominal & $15.7 \%$ & $17.6 \%$ & 0.61 \\
\hline Urinary tract & $26(6.2 \%)$ & $10(4.8 \%)$ & 0.59 \\
\hline Catheter-related & $5.0 \%$ & $3.3 \%$ & 0.46 \\
\hline \multicolumn{4}{|l|}{ Pathogens } \\
\hline Gram-negative bacteria & $108(25.7 \%)$ & $67(31.9 \%)$ & 0.12 \\
\hline Gram-positive bacteria & $60(14.3 \%)$ & $21(10.0 \%)$ & 0.69 \\
\hline Aspergillus & $46(10.9 \%)$ & $23(11.0 \%)$ & 1.00 \\
\hline Pneumocystis & $20(4.8 \%)$ & $2(1.0 \%)$ & 0.02 \\
\hline
\end{tabular}


Table 1 continued

\begin{tabular}{|c|c|c|c|}
\hline Characteristics & $\begin{array}{l}\text { No RBC transfusion } \\
(n=421)\end{array}$ & $\begin{array}{l}\text { RBC transfusion } \\
(n=210)\end{array}$ & $p$ \\
\hline \multicolumn{4}{|l|}{ Life-supporting interventions } \\
\hline Vasopressive drugs & $243(57.7 \%)$ & $147(70 \%)$ & 0.004 \\
\hline Invasive ventilation & $205(48.7 \%)$ & $116(55.2 \%)$ & 0.01 \\
\hline Renal replacement therapy & $92(22.2 \%)$ & $62(30.5 \%)$ & 0.03 \\
\hline \multicolumn{4}{|l|}{ Platelet transfusions } \\
\hline Day 1 & $70(16.6 \%)$ & $96(45.7 \%)$ & $<0.001$ \\
\hline Day 2 & $58(13.7 \%)$ & $82(39.0 \%)$ & $<0.001$ \\
\hline \multicolumn{4}{|l|}{ Mortality } \\
\hline ICU mortality & $106(25.2 \%)$ & $82(39.0 \%)$ & $<0.001$ \\
\hline Hospital mortality & $154(36.6 \%)$ & 107 (51.0\%) & $<0.001$ \\
\hline
\end{tabular}

ICU intensive care unit, $R B C$ red blood cell, SOFA sequential organ failure assessment

or complete remission was associated with improved survival (Table 3).

In order to refine the statistical adjustment between non-transfused and transfused patients, we built a propensity score of being transfused during the first two days following ICU admission. The propensity score was based on hemoglobin level at the time of ICU admission and on the following characteristics: age, gender, performance status, days since hospital admission, allogeneic hematopoietic stem cell transplantation, hematological malignancy type and status, time between its diagnosis and ICU admission, time between hospital and ICU admissions, neutropenia, aspergillosis, chemotherapy, admission SOFA score and septic shock. This score allowed matching 142 patients who did receive $\mathrm{RBC}$ transfusion as part of the initial resuscitation to 142 counterparts who did not. As shown in Fig. 2b, propensity score-matched transfused and non-transfused patients displayed similar survival trends (OR for inhospital death 1.25 [0.75-2.05], $\mathrm{p}=0.39$ ). When including all 631 patients in a weighting analysis, day $1 / 2 \mathrm{RBC}$ transfusion was still associated with increased hospital mortality (OR 1.64 [1.05-2.57], $\mathrm{p}=0.03$ ).

\section{Discussion}

There is no doubt that the prognosis of critically ill patients with hematological malignancies has dramatically improved, and admission to the ICU is now viewed as a bridge to cure rather than a terminal process. The reasons for this trend are multiple, including general improvements in the prognosis of cancer, better and early identification of patients likely to benefit from intensive care and advances in the management of acute life-threatening disorders [18]. However, severe infections resulting in shock and/or acute respiratory failure represent dreaded complications in cancer patients and still account for a large number of deaths regardless of the stage of malignancy. It is clear that cancer patients already benefited from advances in the field of sepsis, but it remains a major area for improvement for this vulnerable population. Nevertheless, such immunocompromised patients were either underrepresented or even excluded from the leading clinical trials in severe sepsis and septic shock. Whether they are entitled to strictly similar management as non-immunocompromised patients is questionable.

The poor prognosis of hematological patients with severe sepsis is commonly attributed to the underlying immune defects resulting in impaired and delayed pathogen clearance, but additional mechanisms related to the disease itself or to its treatment may also worsen organ failures. For instance, endothelial or cardiac toxicity by chemotherapy and radiotherapy may contribute to the pathophysiology of acute circulatory failure [19], while lactic acidosis may not only reflect systemic tissue hypoperfusion but might also result from altered metabolism of tumor cells. However, intensity and duration or vasopressor support appear quite similar in cancer patients, either untreated or treated with chemotherapy, and in patients free of cancer but harboring alternative comorbidities [20]. Furthermore, microvascular derangements have been reported in non-septic patients with chemotherapy-induced neutropenia, albeit microcirculatory alterations induced by septic shock appeared quite similar in neutropenic and non-neutropenic patients [21]. Most importantly, cancer patients commonly display chronic anemia likely to contribute to the impaired oxygen delivery encountered in severe sepsis and septic shock and appear then liable to RBC transfusion early in the course of hemodynamic resuscitation.

The general practice of RBC transfusion in the ICU is guided by the apparently opposite objectives of preserving an appropriate tissue oxygenation while minimizing the number of packed red cells transfused. 
Table 2 Characteristics of in-hospital survivors and deceased

\begin{tabular}{|c|c|c|c|}
\hline Characteristics & $\begin{array}{l}\text { In-hospital survivors } \\
(n=370)\end{array}$ & $\begin{array}{l}\text { In-hospital deceased } \\
(n=261)\end{array}$ & $p$ \\
\hline \multicolumn{4}{|l|}{ Demographics } \\
\hline Age (years) & $58.5[47-67.75]$ & $63[52-71]$ & 0.01 \\
\hline Male gender & $240(64.9 \%)$ & $166(63.6 \%)$ & 0.81 \\
\hline \multicolumn{4}{|l|}{ Comorbid illnesses } \\
\hline Performance status 3-4 & $61(16.5 \%)$ & $77(29.5 \%)$ & 0.0001 \\
\hline Charlson comorbidity index & $4[2-5]$ & $4[3-6]$ & 0.008 \\
\hline Underlying malignancy & & & 0.90 \\
\hline Lymphoid disease & $179(48.4 \%)$ & $131(50.2 \%)$ & \\
\hline Myeloid disease & $121(32.7 \%)$ & $83(31.8 \%)$ & \\
\hline Time between diagnosis and ICU admission (days) & $91[14 ; 444]$ & $90[11 ; 396]$ & 0.58 \\
\hline Hematopoietic stem cell transplantation & & & 0.04 \\
\hline Autologous & $52(14.1 \%)$ & $24(9.2 \%)$ & \\
\hline Allogeneic & $55(14.9 \%)$ & $55(21.1 \%)$ & \\
\hline Malignancy status & & & 0.019 \\
\hline Newly diagnosed & $106(28.7 \%)$ & $84(32.2 \%)$ & \\
\hline Partial/complete remission & $116(31.4 \%)$ & $53(21.4 \%)$ & \\
\hline Time between hospital and ICU admissions (days) & $4[0-16]$ & $9[1-25]$ & $<0.0001$ \\
\hline \multicolumn{4}{|l|}{ ICU admission characteristics } \\
\hline SOFA score & $6[4-8]$ & $8[5-11.75]$ & $<0.0001$ \\
\hline Neutropenia & $125(33.8 \%)$ & $104(39.9 \%)$ & 0.14 \\
\hline Lactate (mmol/L) & $1.9(1.125-3.575)$ & $2.4[1.6-5.6]$ & 0.0001 \\
\hline \multicolumn{4}{|l|}{ Hemoglobin level (g/dL) } \\
\hline Day 1 & $9.2[8-10.7]$ & $8.9[7.8-10.2]$ & 0.02 \\
\hline Day 2 & $9.2[8.3-10.2]$ & $9.1[8.3-10]$ & 0.33 \\
\hline Day 3 & $9[8.1-10]$ & $8.9[8.2-9.975]$ & 0.88 \\
\hline Day 7 & $8.8[8.1-9.8]$ & $8.8[8.3-9.95]$ & 0.53 \\
\hline \multicolumn{4}{|l|}{ RBC transfusion } \\
\hline Day 1 and/or 2 & $103(27.8 \%)$ & $107(41 \%)$ & 0.0008 \\
\hline Day 3 & $42(12.4 \%)$ & $39(17.3 \%)$ & 0.13 \\
\hline Day 7 & $16(10.6 \%)$ & $21(16.7 \%)$ & 0.19 \\
\hline \multicolumn{4}{|l|}{ Source of infection } \\
\hline Pneumonia & $190(51.4 \%)$ & $68(64.3 \%)$ & 0.002 \\
\hline Abdominal & $69(18.7 \%)$ & $34(13.0 \%)$ & 0.076 \\
\hline Urinary tract & $21(5.7 \%)$ & $15(5.8 \%)$ & 1.00 \\
\hline Catheter-related & $21(5.7 \%)$ & $7(2.7 \%)$ & 0.11 \\
\hline \multicolumn{4}{|l|}{ Pathogens } \\
\hline Gram-negative bacteria & $101(27.3 \%)$ & $74(28.4 \%)$ & 0.84 \\
\hline Gram-positive bacteria & $56(15.1 \%)$ & $25(9.6 \%)$ & 0.053 \\
\hline Aspergillus & $27(7.3 \%)$ & $42(16.1 \%)$ & 0.0008 \\
\hline Pneumocystis & $17(4.6 \%)$ & $5(1.9 \%)$ & 0.11 \\
\hline \multicolumn{4}{|l|}{ Life-supporting interventions } \\
\hline Vasopressive drugs & $184(49.7 \%)$ & $206(78.9 \%)$ & $<0.0001$ \\
\hline Invasive ventilation & $124(33.5 \%)$ & $197(75.5)$ & $<0.0001$ \\
\hline Renal replacement therapy & $56(15.4 \%)$ & $98(38.7 \%)$ & $<0.0001$ \\
\hline
\end{tabular}

Studies investigating RBC transfusion in the ICU have so far been performed in general populations in which anemia is mostly acquired during the ICU stay as a result of dilution and blood loss, associated with an impaired erythropoietic response. In 1999, the pivotal TRICC study by Hebert and colleagues showed that a restrictive 

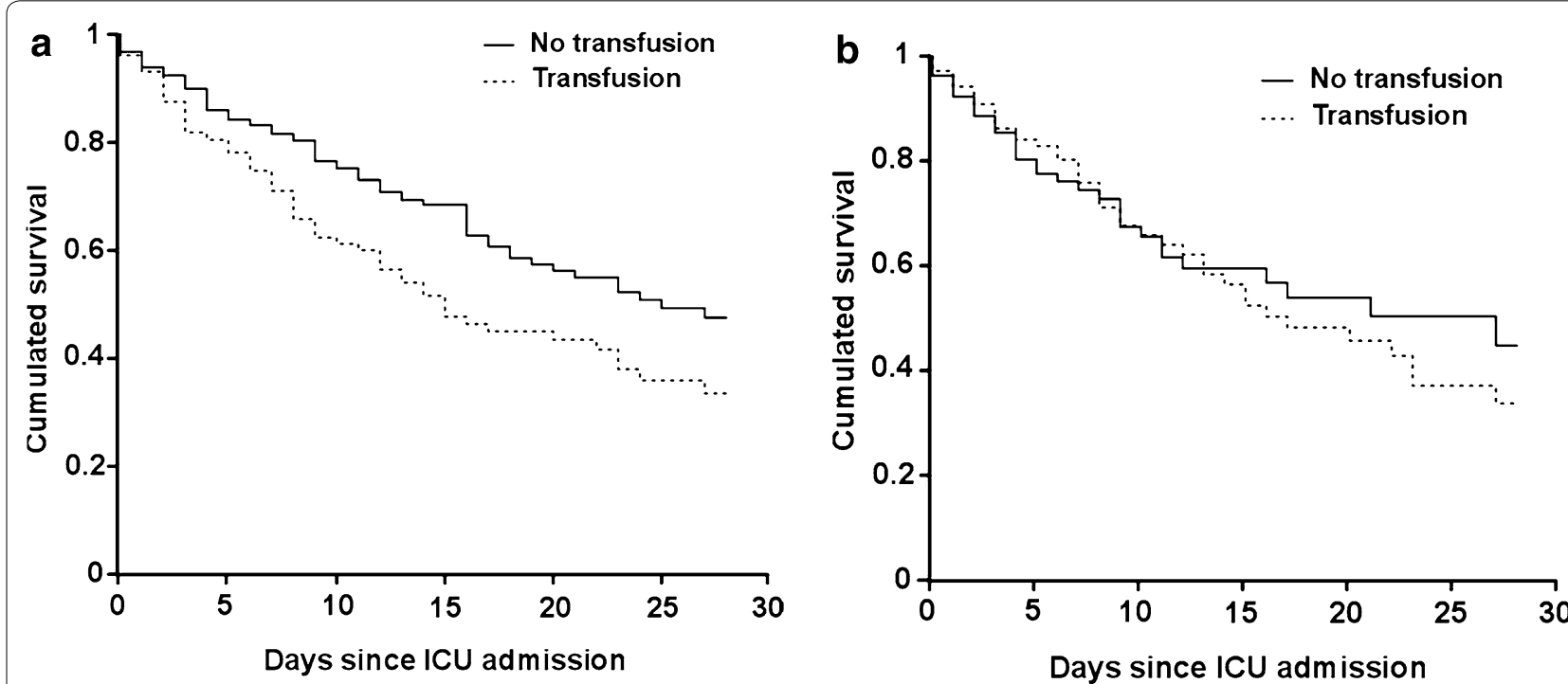

Fig. 2 Survival estimates in non-transfused and transfused patients. Crude (a) and propensity score-adjusted (b) survival estimates in patients who did or did not receive red blood cell transfusion during the first two days of resuscitation. a Encompasses the whole cohort (631 patients distributed into 421 non-transfused and 210 transfused). b Includes 142 transfused patients with 142 propensity score-matched non-transfused counterparts. ICU intensive care unit

Table 3 Determinants of hospital mortality: multivariate analysis

\begin{tabular}{lcc}
\hline Characteristics & Odds ratio (95\% CI) & $\boldsymbol{p}$ \\
\hline RBC transfusion at day 1/2 & $1.52(1.03-2.26)$ & 0.03 \\
Hemoglobin level at ICU admission & $1.0(0.95-1.06)$ & 0.87 \\
Performance status 3-4 & $1.97(1.29-3.02)$ & 0.002 \\
Lactate level at ICU admission & $1.01(0.96-1.05)$ & 0.79 \\
SOFA score at ICU admission & $1.14(1.1-1.21)$ & $<0.001$ \\
Septic shock & $1.30(0.86-1.96)$ & 0.21 \\
Allogeneic HSCT recipient & $2.14(1.28-3.57)$ & 0.004 \\
Remission & $0.53(0.34-0.84)$ & 0.007 \\
Time between hospital and ICU & $1.69(1.14-2.51)$ & 0.009 \\
admissions $>1$ day & & 0.02 \\
\hline Invasive aspergillosis & $1.91(1.08-3.4)$ & \\
\hline
\end{tabular}

All variables entered into the model appear in the table. Hosmer-Lemeshow goodness of fit of the multivariate model was tested on each imputed dataset, with $\mathrm{p}$ values ranging from 0.22 to 0.96

$\mathrm{Cl}$ confidence interval, $\mathrm{HSCT}$ hematopoietic stem cell transplantation, ICU intensive care unit, $R B C$ red blood cell, OR odds ratio, SOFA sequential organ failure assessment

strategy of non-leucodepleted RBC transfusion to maintain hemoglobin above $7 \mathrm{~g} / \mathrm{dL}$ was at least as effective as a liberal transfusion strategy aimed to maintain hemoglobin $>10 \mathrm{~g} / \mathrm{dL}$ in critically ill patients [12]. As of today, the recommendations for $\mathrm{RBC}$ transfusion in the ICU remain largely based on this study. Of note, this study excluded patients with a previous history of chronic anemia.
However, some studies challenged the general implementation of this restrictive strategy and suggested that a higher transfusion threshold might be beneficial in septic patients for whom oxygen delivery is of paramount importance. This was first derived from the study by Rivers and colleagues, in which most EGDT-treated patients had received $\mathrm{RBC}$ transfusion to maintain a hematocrit level above 30\% [5]. Since then, three studies using propensity-adjusted analysis also reported that RBC transfusion was associated with improved survival in septic shock [22-24]. Furthermore, a Brazilian monocenter randomized study reported that a liberal RBC transfusion strategy (hemoglobin $>9 \mathrm{~g} / \mathrm{dL}$ ) versus a restrictive strategy (hemoglobin $>7 \mathrm{~g} / \mathrm{dL}$ ) improved survival in critically ill patients admitted to the ICU following major cancer surgery [25]. The reasons for this finding remain intriguing, but possibly related to a lower incidence of both cardiovascular complications and superinfections. The same team reported a benefit from a liberal transfusion strategy applied throughout the ICU stay in solid cancer patients with septic shock [26]. A multicenter randomized Scandinavian study addressed the transfusion policy in septic shock patients, of whom $7.5 \%$ had hematological malignancies and $9.5 \%$ had metastatic cancer. Patients were randomized to either a restrictive or a liberal transfusion policy to maintain hemoglobin levels higher than 7 or $9 \mathrm{~g} / \mathrm{dL}$, respectively [13]. Similar survival rates were reported in the restrictive and liberal randomization arms. Subgroup analysis in patients with 
hematological malignancies or metastatic cancer also retrieved similar survival rates in both randomization arms [27]. However, it should be emphasized that most patients had already been efficiently resuscitated and restored tissue oxygenation at the time of randomization. Although this study suggests that a restrictive transfusion policy can be safely implemented in most patients with septic shock, we do think that it does not provide a definite answer for patients with persistent and/or marked circulatory failure.

The trend in increased mortality in transfused patients is the most intriguing result of our study. Although this is in line with several case-control studies which suggested that RBC transfusion was associated with higher mortality and increased incidence of ICU-acquired complications in critically ill patients, the interpretation of this finding deserves caution. On one hand, this could suggest that requirements of $\mathrm{RBC}$ transfusion, presumably imposed by persistent tissue dysoxia, could represent a very potent prognostic factor even when adjusted to the classical determinants of death in this setting. On the other hand, there are considerable interindividual variations in the microcirculatory and tissue oxygenation responses to $\mathrm{RBC}$ transfusion [28, 29]. Increase in blood viscosity by RBC transfusion and storage lesions can result in paradoxical impairment on microcirculation and tissue oxygenation. While not being immediately fully efficient for oxygen delivery to tissue, red cells may then sludge within capillaries, interact with endothelial cells and promote inflammatory processes [30,31]. However, recent studies using leucodepleted packed red cells did not retrieve any impact of storage duration on restoration of tissue oxygenation or survival status in critically ill patients with anemia [32, 33]. Finally, RBC transfusion may represent a risk factor for hospital-acquired infection as a result of transfusion-induced immunomodulation $[34,35]$. Although we could not reliably collect the incidence of ICU-acquired complications, it is noteworthy that the non-adjusted survival curves of transfused and non-transfused patients forked as early as three days after ICU admission, suggesting that the poor impact of $\mathrm{RBC}$ transfusion was related to early events rather than secondary ICU-acquired complications.

One strength of this study is the prospective collection of data, although it was a secondary analysis of a database that was not designed to this specific aim. In general, data from the first three days were complete and accurate, but data collected later on were less detailed. Thus, the estimation of packed red cells transfused within the first three days was accurate, whereas daily transfusions thereafter were not collected. Nonetheless, neither the volume of fluid loading nor the fluid balance was accurately recorded in the database. In the same way, the incidence of delayed ICU-acquired infectious and non-infectious complications and the definite causes of death could not be reliably estimated. In the absence of guidelines, indications of RBC transfusion in this setting were probably quite inconsistent across centers. Hemoglobin levels in the RBC transfusion group were often higher than the recommended $7 \mathrm{~g} / \mathrm{dl}$ threshold. However, this was an observational study reflecting routine practice. With respect to the lower hemoglobin levels and the severity of circulatory dysfunctions in transfused patients, it is likely that physicians followed a common pragmatic decision-making process at the bedside, based not only on a sole hemoglobin level but also on markers of tissue dysoxia. However, such an observational study can only provide exploratory data and statistical link, but is no substitute to prospective interventional studies.

\section{Conclusion}

$\mathrm{RBC}$ transfusions are frequently used as part of the initial resuscitation of severe sepsis or septic shock in patients with hematological malignancies. Although RBC transfusion was preferentially administrated to the most severe patients, we found it possibly associated with an increased risk of death. Since the definite indications of $\mathrm{RBC}$ transfusions in resuscitation of severe sepsis remain questionable, cancer patients with a high prevalence of underlying anemia represent a relevant subgroup to address this question in a prospective manner.

\section{Additional file}

Additional file 1: Fig. S1. Arterial lactate levels in non-transfused and transfused patients. RBC (red blood cell).

\section{Abbreviations}

EGDT: early goal-directed therapy; HSCT: hematopoietic stem cell transplantation; ICU: intensive care unit; RBC: red blood cell; SOFA: sepsis-related organ failure assessment.

\section{Authors' contributions}

AM, MRR, EA and FP made substantial contributions to the conception of the work, the acquisition, analysis and interpretation of data for the work. They drafted the work and revised it critically for important intellectual content.

They gave final approval of the version to be published. They agree to be accountable for all aspects of the work in ensuring that questions related to the accuracy or integrity of any part of the work are appropriately investigated and resolved. $\mathrm{VL}, \mathrm{DM}, \mathrm{AK}, \mathrm{JM}, \mathrm{FV}, \mathrm{MN}, \mathrm{FB}, \mathrm{AR}, \mathrm{CL}, \mathrm{PP}, \mathrm{AR}, \mathrm{APM}, \mathrm{DB}, \mathrm{RH}, \mathrm{MJ}, \mathrm{MD}$ made substantial contributions to the acquisition of data for the work. They revised the work critically for important intellectual content. They gave final approval of the version to be published. They agree to be accountable for all aspects of the work in ensuring that questions related to the accuracy or integrity of any part of the work are appropriately investigated and resolved. All authors read and approved the final manuscript.

Presented at the congress "Réanimation 2016" of the French Intensive Care Society, 13-15 January 2016, Paris, France. 


\begin{abstract}
Author details
1 Réanimation médicale, hôpital Cochin, Assistance Publique-Hôpitaux de Paris (AP-HP) and Université Paris Descartes, 27 rue du Faubourg Saint-Jacques, 75014 Paris, France. ${ }^{2}$ Département de biostatistiques, Hôpital Saint-Louis, APHP and Université Paris Diderot, Paris, France. ${ }^{3}$ Réanimation médicale, Hôpital Saint-Louis, AP-HP and Université Paris Diderot, Paris, France. ${ }^{4}$ Département d'anesthésie-réanimation, Institut Paoli-Calmettes, Marseille, France. ${ }^{5}$ Réanimation médicale et médecine hyperbare, CHU d'Angers, Angers, France. ${ }^{6}$ Réanimation médicale, Hôpital de la Pitié-Salpêtrière, AP-HP and Université Pierre et Marie Curie, Paris, France. ${ }^{7}$ Réanimation polyvalente, Centre Hospitalier Intercommunal, Montfermeil, France. ${ }^{8}$ Centre Hospitalier de Roubaix, Roubaix, France. ${ }^{9}$ Réanimation polyvalente, Hôpital André Mignot, Le Chesnay, France. ${ }^{10}$ Unité de soins intensifs respiratoires, Hôpital Cochin, AP-HP and Université Paris Descartes, Paris, France. ${ }^{11}$ Réanimation polyvalente, Centre Hospitalier Départemental, La Roche-sur-Yon, France. ${ }^{12}$ Réanimation médicale, Hôpital Brabois, Nancy, France. ${ }^{13}$ Réanimation médicale, Centre Hospitalier de Brest, Brest, France. ${ }^{14}$ Service des soins intensifs et urgences oncologiques, Institut Jules Bordet, Brussels, Belgium. ${ }^{15}$ Ghent University Hospital, Ghent, Belgium. ${ }^{16}$ Réanimation médicale, CHU Grenoble-Alpes, Grenoble, France. ${ }^{17}$ Université de Lille and Réanimation Polyvalente, CHU de Lille, Lille, France. ${ }^{18}$ Réanimation médicale, Centre Hospitalier de Saint-Etienne, Saint-Etienne, France.
\end{abstract}

\section{Competing interests}

The authors declare that they have no competing interests.

\section{Ethics approval}

The study was approved by the appropriate ethics committees in France and Belgium.

\section{Funding}

French Ministry of Health No. PHRC AOM 08235 and French Intensive Care Society.

\section{Publisher's Note}

Springer Nature remains neutral with regard to jurisdictional claims in published maps and institutional affiliations.

Received: 25 February 2017 Accepted: 2 June 2017

Published online: 12 June 2017

\section{References}

1. Larché J, Azoulay E, Fieux F, Mesnard L, Moreau D, Thiery G, et al. Improved survival of critically ill cancer patients with septic shock. Intensive Care Med. 2003;29(10):1688-95.

2. Pène F, Percheron S, Lemiale V, Viallon V, Claessens Y-E, Marqué S, et al. Temporal changes in management and outcome of septic shock in patients with malignancies in the intensive care unit. Crit Care Med. 2008;36(3):690-6.

3. Zuber B, Tran T-C, Aegerter P, Grimaldi D, Charpentier J, Guidet B, et al. Impact of case volume on survival of septic shock in patients with malignancies. Crit Care Med. 2012;40(1):55-62.

4. Legrand M, Max A, Peigne V, Mariotte E, Canet E, Debrumetz A, et al. Survival in neutropenic patients with severe sepsis or septic shock. Crit Care Med. 2012;40(1):43-9.

5. Rivers E, Nguyen B, Havstad S, Ressler J, Muzzin A, Knoblich B, et al. Early goal-directed therapy in the treatment of severe sepsis and septic shock. N Engl J Med. 2001;345(19):1368-77.

6. Investigators ProCESS, Yealy DM, Kellum JA, Huang DT, Barnato AE, Weissfeld LA, et al. A randomized trial of protocol-based care for early septic shock. N Engl J Med. 2014;370(18):1683-93.

7. ARISE Investigators, ANZICS Clinical Trials Group, Peake SL, Delaney A, Bailey M, Bellomo R, et al. Goal-directed resuscitation for patients with early septic shock. N Engl J Med. 2014;371(16):1496-506.

8. Mouncey PR, Osborn TM, Power GS, Harrison DA, Sadique MZ, Grieve RD, et al. Trial of early, goal-directed resuscitation for septic shock. N Engl J Med. 2015;372(14):1301-11.
9. Dupuis C, Sonneville R, Adrie C, Gros A, Darmon M, Bouadma L, et al. Impact of transfusion on patients with sepsis admitted in intensive care unit: a systematic review and meta-analysis. Ann Intensive Care. 2017;7(1):5.

10. Dellinger RP, Levy MM, Rhodes A, Annane D, Gerlach H, Opal SM, et al. Surviving Sepsis Campaign: international guidelines for management of severe sepsis and septic shock, 2012. Intensive Care Med. 2013;39(2):165-228.

11. Daviaud F, Grimaldi D, Dechartres A, Charpentier J, Geri G, Marin N, et al. Timing and causes of death in septic shock. Ann Intensive Care. 2015;5(1):16.

12. Hébert PC, Wells G, Blajchman MA, Marshall J, Martin C, Pagliarello G, et al. A multicenter, randomized, controlled clinical trial of transfusion requirements in critical care. Transfusion Requirements in Critical Care Investigators, Canadian Critical Care Trials Group. N Engl J Med. 1999;340(6):409-17.

13. Holst LB, Haase N, Wetterslev J, Wernerman J, Guttormsen AB, Karlsson S, et al. Lower versus higher hemoglobin threshold for transfusion in septic shock. N Engl J Med. 2014;371(15):1381-91.

14. Carson JL, Stanworth SJ, Roubinian N, Fergusson DA, Triulzi D, Doree C, et al. Transfusion thresholds and other strategies for guiding allogeneic red blood cell transfusion. In: Cochrane database of systematic reviews [Internet]. Wiley; 2016 [cited 2017 Mar 16]. http://onlinelibrary.wiley.com/ doi/10.1002/14651858.CD002042.pub4/abstract.

15. Azoulay E, Mokart D, Pène F, Lambert J, Kouatchet A, Mayaux J, et al. Outcomes of critically ill patients with hematologic malignancies: prospective multicenter data from France and Belgium - a groupe de recherche respiratoire en réanimation onco-hématologique study. J Clin Oncol. 2013;31(22):2810-8.

16. Vincent JL, Moreno R, Takala J, Willatts S, De Mendonça A, Bruining $H$, et al. The SOFA (Sepsis-related Organ Failure Assessment) score to describe organ dysfunction/failure. On behalf of the Working Group on Sepsis-Related Problems of the European Society of Intensive Care Medicine. Intensive Care Med. 1996;22(7):707-10.

17. Austin PC. Some methods of propensity-score matching had superior performance to others: results of an empirical investigation and Monte Carlo simulations. Biom J. 2009;51(1):171-84.

18. Azoulay E, Pène F, Darmon M, Lengliné E, Benoit D, Soares $M$, et al. Managing critically III hematology patients: time to think differently. Blood Rev. 2015;29(6):359-67.

19. Mokart D, Sannini A, Brun J-P, Faucher M, Blaise D, Blache J-L, et al. $\mathrm{N}$-terminal pro-brain natriuretic peptide as an early prognostic factor in cancer patients developing septic shock. Crit Care. 2007;11(2):R37.

20. Schnell D, Besset S, Lengliné E, Maziers N, Zafrani L, Reuter D, et al. Impact of a recent chemotherapy on the duration and intensity of the norepinephrine support during septic shock. Shock. 2013;39(2):138-43.

21. Karvunidis T, Chvojka J, Lysak D, Sykora R, Krouzecky A, Radej J, et al. Septic shock and chemotherapy-induced cytopenia: effects on microcirculation. Intensive Care Med. 2012;38(8):1336-44.

22. Vincent J-L, Sakr Y, Sprung C, Harboe S, Damas P. Sepsis Occurrence in Acutely III Patients (SOAP) Investigators. Are blood transfusions associated with greater mortality rates? Results of the Sepsis Occurrence in Acutely III Patients study. Anesthesiology. 2008;108(1):31-9.

23. Park DW, Chun B-C, Kwon S-S, Yoon YK, Choi WS, Sohn JW, et al. Red blood cell transfusions are associated with lower mortality in patients with severe sepsis and septic shock: a propensity-matched analysis. Crit Care Med. 2012;40(12):3140-5.

24. Mark DG, Morehouse JW, Hung Y-Y, Kene MV, Elms AR, Liu V, et al. Inhospital mortality following treatment with red blood cell transfusion or inotropic therapy during early goal-directed therapy for septic shock: a retrospective propensity-adjusted analysis. Crit Care. 2014;18(5):496.

25. de Almeida JP, Vincent J-L, Galas FRBG, de Almeida EPM, Fukushima JT, Osawa EA, et al. Transfusion requirements in surgical oncology patients: a prospective, randomized controlled trial. Anesthesiology. 2015;122(1):29-38.

26. Bergamin FS, Almeida JP, Landoni G, Galas FRBG, Fukushima JT, Fominskiy E, et al. Liberal versus restrictive transfusion strategy in critically ill oncologic patients: the transfusion requirements in critically ill oncologic patients randomized controlled trial. Crit Care Med. 2017. doi:10.1097/ CCM.00000000000002283. 
27. Rygård SL, Holst LB, Wetterslev J, Johansson PI, Perner A, TRISS Trial Group, et al. Higher vs. lower haemoglobin threshold for transfusion in septic shock: subgroup analyses of the TRISS trial. Acta Anaesthesiol Scand. 2017;61(2):166-75.

28. Sakr Y, Chierego M, Piagnerelli M, Verdant C, Dubois M-J, Koch M, et al. Microvascular response to red blood cell transfusion in patients with severe sepsis. Crit Care Med. 2007;35(7):1639-44

29. Kopterides P, Theodorakopoulou M, Nikitas N, Ilias I, Vassiliadi DA, Orfanos $\mathrm{SE}$, et al. Red blood cell transfusion affects microdialysis-assessed interstitial lactate/pyruvate ratio in critically ill patients with late sepsis. Intensive Care Med. 2012;38(11):1843-50.

30. Marik PE, Sibbald WJ. Effect of stored-blood transfusion on oxygen delivery in patients with sepsis. JAMA. 1993;269(23):3024-9.

31. Aubron C, Nichol A, Cooper DJ, Bellomo R. Age of red blood cells and transfusion in critically ill patients. Ann Intensive Care. 2013;3(1):2.
32. Lacroix J, Hébert PC, Fergusson DA, Tinmouth A, Cook DJ, Marshall JC, et al. Age of transfused blood in critically ill adults. N Engl J Med. 2015;372(15):1410-8

33. Dhabangi A, Ainomugisha B, Cserti-Gazdewich C, Ddungu $H$, Kyeyune $D$, Musisi E, et al. Effect of transfusion of red blood cells with longer vs shorter storage duration on elevated blood lactate levels in children with severe anemia: the total randomized clinical trial. JAMA. 2015;314(23):2514-23.

34. Shorr AF, Jackson WL, Kelly KM, Fu M, Kollef MH. Transfusion practice and blood stream infections in critically ill patients. Chest. 2005;127(5):1722-8.

35. Rohde JM, Dimcheff DE, Blumberg N, Saint S, Langa KM, Kuhn L, et al. Health care-associated infection after red blood cell transfusion: a systematic review and meta-analysis. JAMA. 2014;311(13):1317-26.

\section{Submit your manuscript to a SpringerOpen ${ }^{\circ}$ journal and benefit from:}

- Convenient online submission

- Rigorous peer review

- Open access: articles freely available online

- High visibility within the field

- Retaining the copyright to your article

Submit your next manuscript at $\boldsymbol{\nabla}$ springeropen.com 